Villanova School of Business Economics Working Paper \# 2

\title{
Money Holdings, Inflation, and Welfare in a
}

\section{Competitive Market*}

\author{
Scott J. Dressler ${ }^{\dagger}$
}

March 2009

\begin{abstract}
This paper examines an environment where money is essential and agents exchange in perfectly-competitive, Walrasian markets. Agents consume and produce a homogeneous good, but hold money to purchase consumption in the event of a relatively low productivity shock. A Walrasian market delivers a non-degenerate distribution of money holdings across agents and avoids some of the computational difficulties associated with the market and pricing assumptions of bilateral matching and bargaining common to search-theoretic environments. The model is calibrated to long-run US velocity, and the welfare costs of inflation are assessed for variable buyer-seller ratios and persistent states of buying and selling.
\end{abstract}

Keywords: Monetary Policy; Inflation; Welfare; Walrasian Markets JEL: E40; E50

*This paper has benefitted from comments and suggestions by Randall Wright, Miguel Molico, and seminar participants at the 2008 Midwest Macro Meetings, the Univ. of Essex, and the Workshop on Money, Banking, and Payments (FRB Chicago). All errors and omissions are those of the author. First version: January 2009.

${ }^{\dagger}$ Address: Department of Economics and Statistics; Villanova University; 800 Lancaster Avenue; Villanova, PA 19085-1699. Phone: (610) 519-5934. Fax: (610) 519-6054. Email: scott.dressler@villanova.edu 


\section{Introduction}

A large subset of the monetary theory literature stresses the microfoundations for making the holding and use of money essential. ${ }^{1}$ The earliest versions of these environments (e.g. Kiyotaki and Wright, 1989) restrict money holdings to be indivisible, rendering them too simplistic for rigorous quantitative analyses. The reason for such a restriction was that if agents were allowed to hold any amount of money, then the distribution of money holdings across agents would become too complicated of an object to handle. This problem is avoided in subsequent environments (e.g. Shi, 1997 and Lagos and Wright, 2005) through assumptions which render the distribution of money holdings degenerate. While an improvement in quantitative applicability, the assumptions making these models tractable are the same that make them unsuitable for studying the distributional effects of monetary policy.

Studying the distributional effects of monetary policy is difficult in search-theoretic environments because the assumed terms of trade is bilateral bargaining. With bilateral bargaining, the distribution of money holdings is an endogenous state variable because the probability of matching with a relatively wealthy or poor agent influences an agent's present money holdings. ${ }^{2}$ Assessing any distributional effects of monetary policy in models assuming bilateral bargaining therefore comes with a large computational cost. For example, Molico (2006) quantitatively assesses an environment similar to Trejos and Wright (1995) only allows agents to hold perfectly divisible money, and Chiu and Molico (2009) assess the Lagos-Wright model without the assumptions rendering the monetary distribution degenerate. While showing that interesting policy analyses can be gained by facing these computational difficulties head on, the potential for extensions appear formidable.

The goal of this paper is to establish and quantitatively assess an environment where money is essential while avoiding the computational difficulties associated with bilateral

\footnotetext{
${ }^{1}$ In general, the essentiallity of money requires an environment with spatial, temporal, or informational frictions which results in the set of allocations supported with money being larger (and possibly better) than without it.

${ }^{2}$ Examples are Green and Zhou (1998, 2002), Camera and Corbae (1999), Zhou (1999), and Zhu (2003, 2005).
} 
matching and bargaining. Instead of the common assumptions of a pair-wise match followed by a bargaining phase, the model studied here assumes all agents meet in a single (centralized) Walrasian market and take a competitively-determined price as given. Agents receive a shock every period affecting their desire to consume and their ability to produce a homogeneous consumption good. An important distinction from previous search-theoretic environments is that all agents must consume and will be able to produce, but agents may differ due to their productivities and preferences. All agents are granted access to the market, and agents who wish to produce can trade as much of the good as they want against the market. Agents who do not wish to produce must find another way of obtaining consumption, and the assumption of anonymity precludes the use of credit. All agents therefore hold money balances to self-insure against liquidity shocks (i.e. the event they receive a shock negatively affecting their ability to produce).

Assuming Walrasian markets deliver rather significant methodological contributions. Agents no longer need to anticipate who they meet because they trade against the market and take the single market-clearing price as given. The endogenous (and non-degenerate) distribution of money holdings delivered by the model is no longer an endogenous state variable, and the analysis therefore shows that a model with essential money can be analyzed with a computational difficulty on par with early heterogeneous-agent economies such as Huggett (1993) and Aiyagari (1994). ${ }^{3}$ In addition, assuming all agents consume allows the model to be calibrated to match important empirical features such as long-run US velocity. Calibrating models to velocity was previously thought to require an additional (centralized) market where agent's engage in non-monetary consumption as in Lagos and Wright (2005) and Chiu and Molico (2009). ${ }^{4}$ Since the only market here is centralized, monetary and non-monetary trade can be conducted concurrently. Finally, the flexibility of the Walrasian market allows for a rich

\footnotetext{
${ }^{3}$ The important distinction between these environments and the one studied here is that the endogenous state variable (fiat money) is solely produced by the monetary authority and therefore responds to policy in a different way than privately-issued debt or capital.

${ }^{4}$ Matching velocity in an environments where all consumption is assumed monetary is not possible (e.g. Molico, 2006). With a fixed stock of money, there is a negative relationship between prices and quantity which delivers a monetary velocity below empirical observations.
} 
set of alternative environments to assess the welfare implications of monetary policy. Since agents are no longer required to match in bilateral pairs, the analysis considers monetary equilibria with buyer-seller ratios other than one as well as persistent states of buying and selling.

Following the monetary-search literature, the model is quantitatively evaluated by comparing the long-run effects of inflation where prices and the distribution of money holdings are stationary. The results indicate that prices, monetary velocity, and the dispersion of the monetary distribution are all increasing in the money growth (inflation) rate for any buyerseller ratio. The welfare costs of inflation are calculated in a consumption-equivalent manner similar to search-based analyses. When the buyer-seller ratio is equal to one, for example, the model predicts that going from 10 percent inflation to 0 is worth 0.924 percent of total consumption. Additional results indicate that prices are decreasing and welfare costs are increasing in the buyer-seller ratio. With a buyer-seller ratio of 5 , for example, the cost of 10 percent inflation is worth 1.231 percent of total consumption. Interestingly, this version of the model with the highest welfare costs has a monetary distribution which closely matches features of the empirical monetary distribution in the US. Finally, when shocks are persistent, prices and welfare costs are decreasing in the (symmetric) degree of persistence. For example, when high or low productivity agents have a 25 percent chance of being the same next period, the average cost of 10 percent inflation is 2.169 percent of total consumption. When agents receive a 90 percent chance, the average welfare gain of 10 percent inflation is 1.990 percent. These welfare results are decomposed across sellers and buyers to show that the gains / costs of inflation are unevenly distributed among those in persistent states of buying or selling. Clearly, agents in a persistent state of spending money would benefit from high monetary transfers and relatively high inflation, while agents in a persistent state of receiving money would benefit from relatively low inflation.

There are also economically relevant reasons to assume competitive price-taking as an alternative to bilateral bargaining. Competitive pricing with essential money holdings has 
been explored in overlapping generations models by Wallace (1980), turnpike models by Townsend (1980), and many others. More recently, Rocheteau and Wright (2005) consider competitive pricing in a version of the Lagos and Wright model and show that different market structures have different implications for the nature of equilibrium and for the effects of policy. ${ }^{5}$ Therefore, alternative market assumptions when studying monetary policy is just as important as alternative markets in the labor literature. If quantitative analysis of Molico (2006) is monetary economics' analog to the bargaining model of Mortensen and Pissarides (1994), then the present analysis is monetary economics' analog to the price-taking model of Lucas and Prescott (1974).

The remainder of the paper proceeds as follows. Section 2 describes the model and defines and equilibrium. Section 3 outlines the computational algorithm, states the assumed functional forms and calibrations, and details the numerical results. Section 4 concludes.

\section{The Model}

\subsection{The Environment}

Time is discrete with an infinite horizon. There exists a $[0,1]$ continuum of infinitelylived agents who discount the future at rate $\beta \in(0,1)$. All agents consume and produce a perfectly divisible and non-storable good. At the beginning of every period, each agent receives a shock identifying them as one of two possible types. Let the set of agent types be $E=\{b, s\}$. If $e=b$, the agent receives a relatively low productivity shock. If $e=s$, the agent receives a relatively high preference shock. ${ }^{6}$ In general, preferences are given by

$$
U(x, y, e)=u(x, e)-c(y, e),
$$

\footnotetext{
${ }^{5}$ However, Rocheteau and Wright still maintain the assumptions of Lagos and Wright which deliver a degenerate monetary distribution.

${ }^{6}$ This shock could be modeled as separate shocks to preferences and productivity which are assumed to be perfectly correlated. It will be shown that this assumption allows the model to match velocity for an arbitrary number of each type of agent. An exercise below shows that preference shocks can be removed and the model can be calibrated by pinning down the population of agent types.
} 
where $x$ and $y$ denote consumption and production of the good. Assume that $u$ and $c$ are $C^{2}$ and strictly increasing, with $u^{\prime \prime}<0$ and $c^{\prime \prime} \geq 0$. Also, $u(0, e)=-\infty, u^{\prime}(0, e)=\infty$, and $c(0, e)=0 \forall e \in E$. A relatively low productivity shock implies $c(y, b)>c(y, s) \forall y>0$ and $c^{\prime}(\cdot, b)>c^{\prime}(\cdot, s)$, while a relatively high preference shock implies $u(x, s)>u(x, b)$ $\forall x>0$ and $u^{\prime}(\cdot, s)>u^{\prime}(\cdot, b)$. The shock follows a Markov process with stationary transition probability $\pi\left(e^{\prime} \mid e\right)=\operatorname{Pr}\left(e_{t+1}=e^{\prime} \mid e_{t}=e\right)>0 \forall e^{\prime}, e \in E$ that is iid across agents.

There exists a stock of fiat money which is perfectly divisible, costlessly storable, and cannot be produced or consumed by any private individual. Let $\hat{M}^{T}$ denote the beginningof-period money stock, which grows at a constant rate $\mu \geq 0$. The law of motion is given by $\hat{M}^{T \prime}=(1+\mu) \hat{M}^{T}$, where $\hat{M}^{T \prime}$ denotes the stock of money available next period. Agents can hold any nonnegative amount of money $\left(\hat{m}_{e} \in \mathbb{R}_{+}\right)$, and new money is injected into the environment via identical lump-sum transfers $\tau$ to all agents at the beginning of every period.

Agents are granted access to a centralized market after their types are known. Although there is a single consumption good which can be produced by all agents, type $b$ agents may want to consume more than what they wish to produce while type $s$ agents may want to produce more than they wish to consume. In addition, all agents are assumed to be anonymous, which precludes the availability of credit and generates an essential role for money as a medium of exchange. ${ }^{7}$

Let $\hat{P}>0$ denote the nominal price of consumption in the market which all agents take as given. Since the market is Walrasian, agents meet concurrently and trade as much as desired against the market. Let $V(\hat{m}, e ; \hat{P})$ be the expected lifetime utility of a type $e$ agent at the end of a period holding money balances $\hat{m}$ at price $\hat{P}$. The decision problem of

\footnotetext{
${ }^{7}$ These conditions are maintained by Levin (1991), Kocherlakota (1998), and Rocheteau and Wright $(2005)$.
} 
this agent is given by

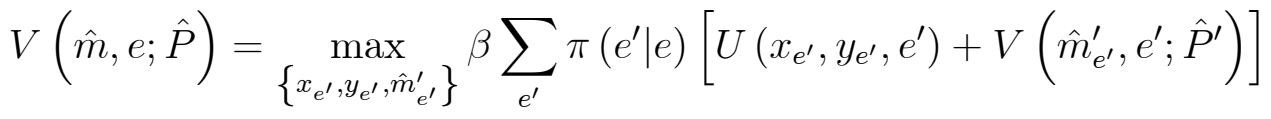

subject to $0 \leq x_{e^{\prime}}, 0 \leq y_{e^{\prime}}, 0 \leq \hat{m}_{e^{\prime}}^{\prime}$, and

$$
\hat{m}_{e^{\prime}}^{\prime}-\hat{P}\left(y_{e^{\prime}}-x_{e^{\prime}}\right) \leq \hat{m}+\tau
$$

The period budget constraint (3) applies for all agents, but the choices of $y_{e^{\prime}}$ and $x_{e^{\prime}}$ will depend on an agent's type. In general, a type $b$ agent with a relatively low productivity shock will choose $x_{b}>y_{b}$ making her a (net) buyer, while a type $s$ agent will choose $y_{s}>x_{s}$ making her a (net) seller. Buyer's will therefore deplete their present money balances while sellers will replenish and self-insure against a future low productivity shock.

It should be noted that having sellers consume is motivated by needing an amount of consumption being non-monetary. In other words, consumption by a seller $\left(x_{s}\right)$ can equally be interpreted as consumption of their own production or simple one-for-one trades with other sellers. ${ }^{8}$ Since these exchanges do not involve money, the preference shock allows the model to match important features of an economy like velocity by keeping output high without placing downward pressure on prices.

\subsection{Equilibrium}

All nominal variables are expressed as fractions of the total end-of-period money stock (e.g. $P=\hat{P} / \hat{M}^{T \prime}$ and $\left.m^{\prime}=\hat{m}^{\prime} / \hat{M}^{T \prime}\right)$. While the short-run dynamics of this economy are certainly of interest, the present analysis focuses on stationary equilibria where the (normalized) price of consumption $P$ and the distribution of money holdings remain constant. In other words, this analysis focuses on the long-run effects of changes in the constant money

\footnotetext{
${ }^{8}$ One can argue that the same types of exchanges take place in the centralized markets of search-theoretic monetary models (i.e. Lagos and Wright, 2005).
} 
growth rate $\mu$.

At the end of every period, agents will be heterogeneous with respect to their type $(e)$ and individual money holdings $(m)$. Agents can be described by their individual state vector $z \in Z$, where $z=(m, e)$. The individual state space is defined as $Z=M \times E$, where $M=\mathbb{R}_{+}$. Let $\psi$ be a probability measure on $\left(S, \beta_{S}\right)$, where $S=\mathbb{R}_{+} \times E$ and $\beta_{S}$ is the Borel $\sigma$-algebra. For $B \in \beta_{S}$, one can think of $\psi(B)$ as the mass of agents with money holdings and types in the set $B$ when the good price is $P$ and the money growth rate is $\mu$.

With the agents' decision rules and the shock process, a transition function $\Theta: \mathbb{R}_{+} \times E \rightarrow$ $[0,1]$ can be constructed. $\Theta(z, B)$ describes the conditional probability that an agent with state $z$ will have an individual state vector lying in $B$ next period. Therefore, a stationary probability measure defined on $\left(S, \beta_{S}\right)$ must satisfy

$$
\psi(B)=\int_{S} \Theta(z, B) d \psi, \forall B \in \beta_{S}
$$

A stationary equilibrium is a list of functions $V(z ; P), m(z ; P), x(z ; P), y(z ; P)$, a probability measure $\psi$, and a market price $P(\mu)$ such that

1. $m(z ; P), x(z ; P)$, and $y(z ; P)$ are optimal decision rules given $P(\mu)$.

2. $\psi$ is a stationary probability measure.

3. The markets for goods and money clear:

$$
\begin{gathered}
\int_{S}[x(z ; P)-y(z ; P)] d \psi=0 \\
\int_{S} m(z ; P) d \psi=1
\end{gathered}
$$

The goods market clearing condition (5) states that the total amount of output produced must equal the total consumed, while the money market clearing condition (6) states that the total amount of money held must be equal to the (normalized) available money stock. 


\section{Numerical Analysis}

\subsection{The Computational Algorithm}

As stated in the introduction, the single market-clearing price delivered by Walrasian markets greatly eases the computational burden of solving for a stationary distribution of money holdings. The algorithm for solving the economy presented here only departs from the algorithm of Huggett (1993) insofar as there are two market clearing conditions (goods and money).

The computational algorithm consists of the following steps:

1. Given $M^{T}=1$ (normalized monetary base), define a grid on the space of money holdings, $\left\{0, m_{1}, m_{2}, \ldots, \bar{m}\right\}$, where $\bar{m}$ is large enough so there is no mass of agents with money holdings $m \geq \bar{m}$ for any probability density satisfying $\int_{S} m d \psi=1 .^{9}$

2. Given a money growth rate $\mu$, select an initial price $P_{0}$ and solve $V\left(z ; P_{0}\right)$ using $(2)$.

3. Define an initial guess for the monetary distribution by choosing a probability measure $\psi_{0}$ satisfying

$$
\int_{S} m d \psi_{0}=1
$$

and draw a large sample (size $\mathrm{N}$ ) from this distribution. ${ }^{10}$

4. Using the decision rules from step 2, update the sample of money holdings until the probability measure has converged. Namely, randomly select agents to become buyers and sellers based on the Markov process, and update each individual's money holdings using $m(z ; P)$ until convergence is achieved. ${ }^{11}$

5. Given the converged probability measure, compute the goods market-clearing condition

$$
\text { (5): } \int_{S}[x(z ; P)-y(z ; P)] d \psi=\delta .
$$

\footnotetext{
${ }^{9}$ The numerical exercises used $\bar{m}=4$.

${ }^{10}$ The numerical exercises used a population size of 60,000 - 100,000 agents depending on the population of each type assumed. The initial distribution of money has no influence on the converged distributions.

${ }^{11}$ Piecewise cubic-hermite interpolation was employed for all function evaluations between the grid points.
} 
- If $\delta \approx 0$, stop. ${ }^{12}$

- If $\delta>0$, then excess demand for goods implies the market price is too low to clear the market. Choose $P_{1}>P_{0}$ and repeat steps 2-5.

- If $\delta<0$, then excess supply for goods implies the market price is too high. Choose $P_{1}<P_{0}$ and repeat steps $2-5$.

One detail worth noting is that the money market-clearing condition (6) is used for each updating of the monetary distribution in step 4. For example, consider an arbitrary price above the market-clearing price. At this price, sellers supply more to the market than buyers demand, implying that sellers will have increased their money holdings more than what buyers have decreased after every iteration. The total stock of money is therefore increasing and the distribution of money holdings is fanning out. This is prevented by imposing (6) at each update of the distribution. After trades have taken place, subtract the total amount of money accepted from the amount spent and denote this as $\tilde{M}$. If $\tilde{M}>0$, then the price is below market clearing and sellers accepted less money than buyers spent and the balance is equally distributed to all buyers end-of-period money holdings. Conversely, if $\tilde{M}<0$, then the price is above market clearing and the balance is equally debited from all sellers end-of-period money holdings. This procedure preserves the initial money stock, and once the distribution has converged, step 5 delivers guidance on a new price so (5) and (6) are satisfied simultaneously.

\footnotetext{
${ }^{12}$ All numerical exercises used a tolerance of $|\delta| \leq 0.001$.
} 


\subsection{Functional Forms and Calibration}

The preferences considered here are similar to those considered by Lagos and Wright (2005) and subsequent others for their centralized markets. The functional forms are:

$$
\begin{gathered}
u(x, e)=\theta_{e} \log (x) \\
c(y, e)=C_{e} y
\end{gathered}
$$

with $\theta_{s}>\theta_{b}$ and $C_{b}>C_{s}$. Stated previously, values of $\theta_{e}$ and $C_{e}$ serve the same purpose here as different utility functions across markets in search-based models; it allows the model to match monetary velocity.

The benchmark economy assumes an annual frequency, and $\beta$ is set to 0.96 corresponding to a four percent real annual interest rate. Type shocks are assumed to have no persistence, implying all agents face an equal probability of becoming a type $e$ agent next period. Defining $\pi(b \mid e)=\sigma$ and $\pi(s \mid e)=1-\sigma \forall e \in E$, the resulting buyer-seller ratio is $\sigma /(1-\sigma)$. The benchmark economy assumes a buyer-seller ratio of one and sets $\sigma=1 / 2$.

For all exercises considered, $\theta_{b}=1, C_{s}=1$, and $C_{b}$ is set large enough to ensure that the production of type $b$ agent does not greatly influence the numerical results $\left(C_{b}=1.0 e^{3}\right) .{ }^{13}$ The amount a seller is willing to consume (i.e. non-monetary consumption) depends on the preference parameter $\theta_{s}$. For $\sigma=1 / 2, \theta_{s}$ is calibrated to 18.15 so the predicted monetary velocity is roughly 5 when the annual money growth rate is 2 percent. This empirical measure of velocity follows Lagos and Wright (2005) and Molico and Chiu (2009) by using M1 as the monetary aggregate.

Before proceeding to the numerical results, it should be noted that the preference shock parameter $\theta_{s}$ is not a crucial feature of the economy. This parameter is pinned down to match velocity while the probability of becoming a buyer $(\sigma)$ can remain a free parameter.

\footnotetext{
${ }^{13}$ When a type $b$ agent has zero money holdings, she has no alternative but to produce for herself. She will therefore choose a quantity $q$ such that the marginal cost of production equals the marginal benefit: $q=\theta_{b} / C_{b}$. Since this is a low probability event, the numerical results are robust to the choice of $C_{b}$.
} 
When $\sigma$ is free, it allows the analysis to consider alternative buyer-seller ratios. A version of the model is considered below where $\theta_{s}=1$ and $\sigma$ is pinned down to match velocity.

\subsection{Numerical Results}

\subsubsection{The Benchmark Economy}

The results for the benchmark model with zero inflation $(\mu=0)$ are illustrated in Figure 1. The value function (upper-left panel) indicates that the marginal value of money is decreasing in the amount of money holdings, implying there are declining incentives for selfinsurance once an agent becomes wealthy. ${ }^{14}$ The amount a seller produces $\left(y_{s}\right)$ is decreasing in her money holdings, while the amount of consumption $\left(x_{s}\right)$ is constant and equal to $\theta_{s}$. Due to the quasi-linear preferences considered, all sellers choose consumption such that the marginal benefit of consumption $\left(\theta_{s} / x_{s}\right)$ is equal to the marginal cost of production (1). In other words, all sellers behave like agents in the centralized market of Lagos and Wright. The same cannot be said for buyers, who instead use their money balances to purchase consumption from sellers.

To understand the results further, note that the value $y_{s}-x_{s}$ becomes negative at a particular amount of monetary wealth. Denote this amount $m^{*}$. Sellers with $m^{*}$ choose to consume or trade their production and make no changes to their money holdings, while sellers with less (more) than $m^{*}$ produce more (less) to replenish (deplete) their money balances. Therefore, all sellers choose $m^{*}$. The lower-right panel of Figure 1 illustrates the stationary monetary distribution. The distribution indicates that 50 percent of the population hold $\mathrm{m}^{*}$, clearly due to the fact that 50 percent of the population are sellers at any given time. The remaining mass points comprise the rest of the population who have been buyers for one or more periods. Therefore, the liquidity constraints of the buyers deliver the non-degenerate distribution.

\footnotetext{
${ }^{14}$ It should be noted that only one value function is illustrated because when type shocks have no persistence: $V(m, b ; P)=V(m, s ; P) \forall m \in M$.
} 
The analysis now turns to the welfare effects of long-run inflation. Define $W(0)$ as the average-expected welfare of all agents in an environment with zero inflation.

$$
\begin{aligned}
W(0) & =\int_{S} V(z ; P(0)) d \psi(0) \\
& =\frac{\beta}{1-\beta} \int_{0}^{\bar{m}}[\sigma U(x, y, b)+(1-\sigma) U(x, y, s)] d \psi(0)
\end{aligned}
$$

Given this measure, the welfare cost of having an inflation rate greater than zero is given by $(1-\Delta(\mu)) \times 100 \%$ where $\Delta(\mu)$ solves

$$
W(0)=\frac{\beta}{1-\beta} \int_{0}^{\bar{m}}[\sigma U(\Delta(\mu) x, y, b)+(1-\sigma) U(\Delta(\mu) x, y, s)] d \psi(\mu) .
$$

In other words, $\Delta(\mu)$ delivers the compensation (in terms of consumption) that agents would need under inflation rate $\mu$ to be just as well off as they were under zero inflation.

The welfare calculations and a variety of other statistics are reported in Table 1. In general, increasing inflation results in an increase in the market price, the dispersion of money holdings, and monetary velocity, as well as a decrease in the average amount consumed by buyers and welfare. The increase in prices and velocity are due to the fact that under larger amounts of inflation, relatively poor buyers are given subsidies of money and now have additional funds with which to demand more consumption. These anticipated subsidies induce buyers to spend more of their present money balances, but induce sellers to offer fewer goods. This results in a more dispersed monetary distribution and delivers the overall decline in welfare. In particular, an agent under 10 percent inflation relative to zero percent would suffer a cost of roughly 0.92 percent of total consumption.

To further illustrate the effects of inflation on the benchmark economy, the monetary distributions under several inflation rates are illustrated in Figure 2. All distributions exhibit a right-tail where 50 percent of the population hold $m^{*}(\mu)$, but $m^{*}(\mu)$ is increasing in the inflation rate. In addition, the distance between the mass points for the remaining buyers are also increasing in the inflation rate due to the increasing good price. Buyers spend larger 

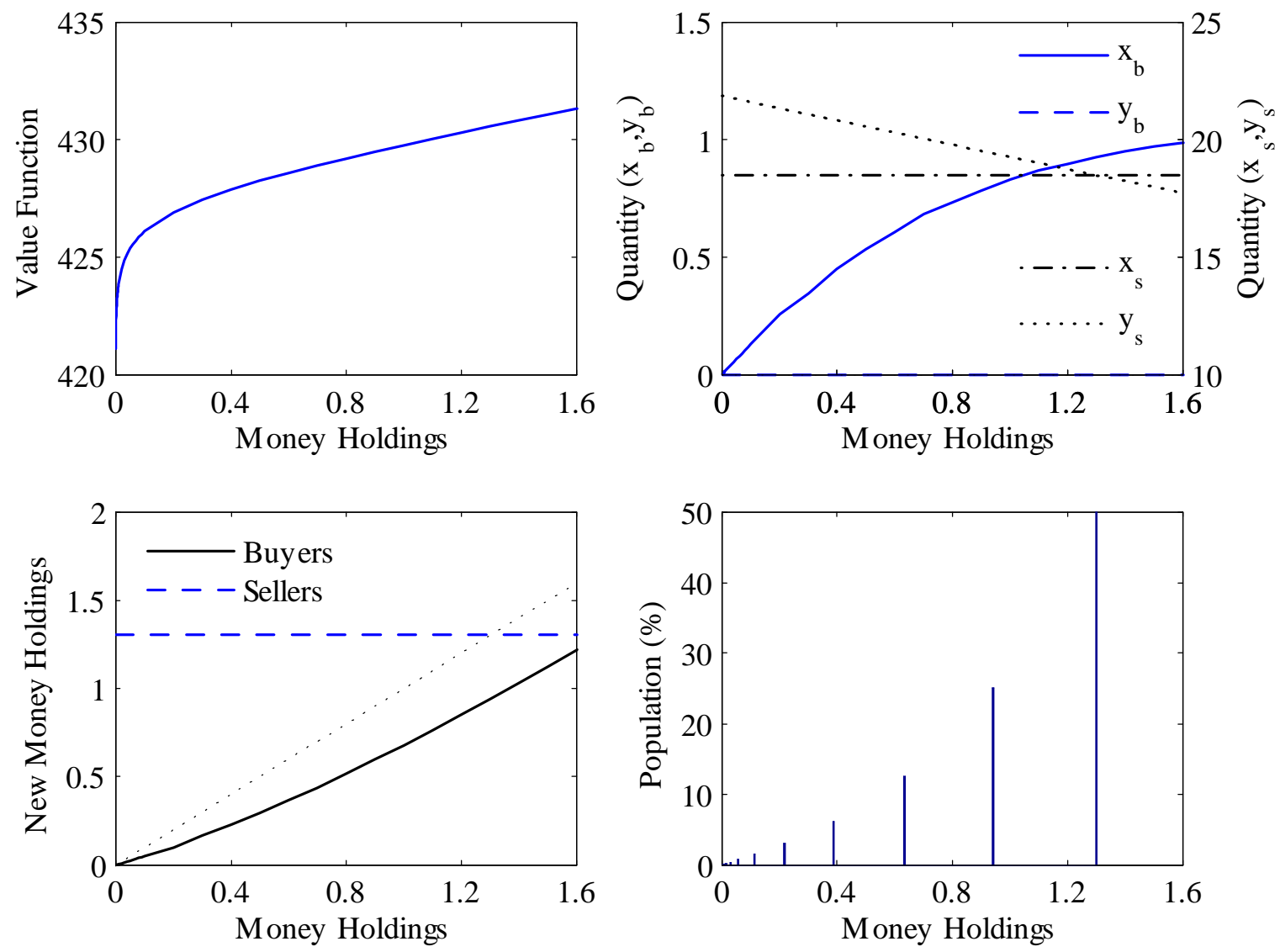

Figure 1: Benchmark economy under zero percent inflation.

portions of their money balances after each successive period of buying.

\subsubsection{Variable Buyer-Seller Ratios}

The analysis now considers the model under different buyer-seller ratios. Type shocks are still assumed to have no persistence $(\pi(b \mid e)=\sigma, \forall e \in E)$. Recalling that the buyerseller ratio is $\sigma /(1-\sigma)$, any buyer-seller ratio can be achieved by altering the probability of receiving a type $b$ shock.

Four alternative buyer-seller ratios are considered. Ratios of $1 / 2$ and 2 were arbitrarily chosen to compare against the benchmark case. The other two ratios were chosen to illustrate important features of the model. First, a buyer-seller ratio of 5 delivers a monetary 

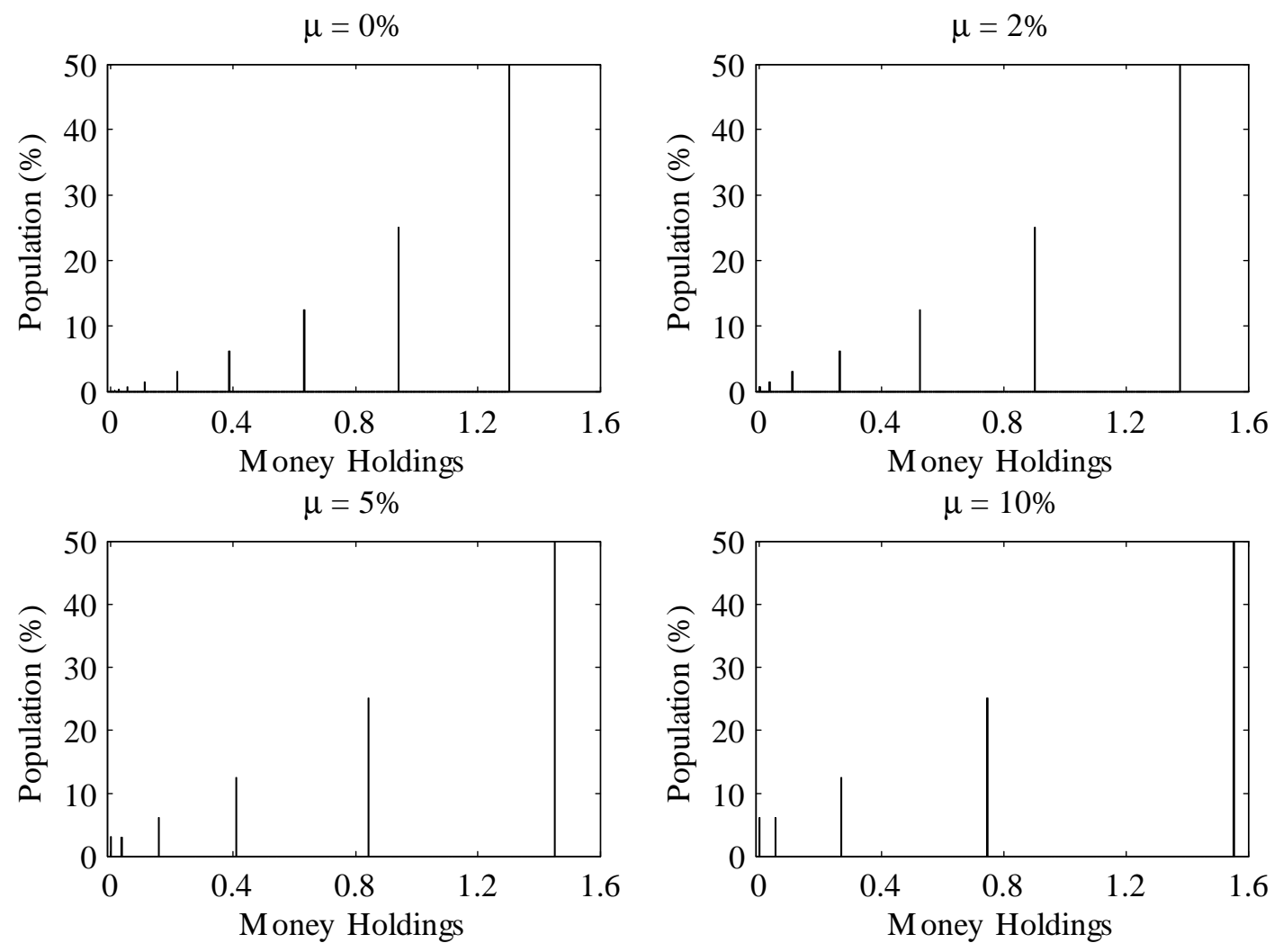

Figure 2: Monetary distributions for benchmark economy; variable inflation rates. 
Table 1: Numerical results for benchmark economy

\begin{tabular}{ccccccc}
\hline \hline$\mu(\%$ ann. $)$ & $P$ & $\operatorname{std}(m)$ & Velocity & $E\left(x_{b}\right)$ & $E\left(x_{s}\right)$ & Welfare (\%) \\
\hline 0 & 0.388 & 0.364 & 3.741 & 0.782 & 18.50 & 0 \\
0.5 & 0.423 & 0.384 & 4.078 & 0.765 & 18.50 & 0.055 \\
1.0 & 0.458 & 0.403 & 4.408 & 0.749 & 18.50 & 0.115 \\
2.0 & 0.524 & 0.436 & 5.034 & 0.720 & 18.50 & 0.232 \\
5.0 & 0.696 & 0.506 & 6.660 & 0.652 & 18.50 & 0.508 \\
10.0 & 0.974 & 0.594 & 9.285 & 0.567 & 18.50 & 0.924 \\
\hline \hline
\end{tabular}

distribution which matches features of an empirical proxy for the monetary distribution in the US. Second, a buyer-seller ratio of 0.0154 allows the model to drop the preference shock (i.e. $\theta_{s}=1$ ) by using $\sigma$ to calibrate the model to the same velocity measure as the benchmark economy. For the other three versions of the model, $\theta_{s}$ was set to $10.15,36.5$, and 95 for the buyer-seller ratios of $1 / 2,2$, and 5 , respectively. Note that the value of $\theta_{s}$ is negatively related to the number of sellers in the economy because the amount of non-monetary consumption (per-seller) must increase. All other parameter values and functional forms are identical to the benchmark case.

The results for prices and welfare are reported in Table 2. Prices are decreasing in the buyer-seller ratio. Increasing the buyer-seller ratio implies that all agents face a higher probability of becoming a buyer next period. This increased probability of needing money balances induces buyers to hold onto more of their present money holdings for next period, as well as induces sellers to acquire additional money holdings. This increase in supply and decrease in demand deliver the decline in the prices.

With respect to the welfare effects of higher inflation, Table 2 indicates nonlinear effects of increasing the buyer-seller ratio. For buyer-seller ratios greater than or equal to 0.5 , the welfare costs of inflation are increasing in the ratio. Similar to the decline in prices, this is due to agents holding onto more money holdings for future consumption. Positive inflation becomes more costly when agents hold onto larger money balances.

The table indicates that this story can also work the other way. In particular, inflation can also be costly when there is a very small probability of becoming a buyer. The first 
two columns of the table shows the price and welfare results under a buyer-seller ratio of 0.0154 , which is pinned down by setting $\theta_{s}=1$. This ratio implies that the market is over 98 percent sellers who are holding money balances which they will rarely need. Therefore, inflation becomes costly because the value of their present money balances will decline by a large amount before they find it worthwhile to use them. In particular, an agent under 10 percent inflation relative to zero percent would suffer a cost of roughly 1.306 percent of total consumption.

The monetary distributions of the model under various buyer-seller ratios are illustrated in Figure 3. Three shared characteristics emerge from these distributions. First, every distribution has a large right tail indicating how many sellers are in the market at any given time. Second, each seller's money balances are increasing in the buyer-seller ratio. Third, the number of remaining mass points of the distribution is increasing in the buyer-seller ratio. While the first characteristic is similar to the benchmark case and due to the linear labor assumption, the other two characteristics are due to the relationship between the buyer-seller ratio and next period's probability of becoming a buyer. The higher an agent's chance of being a buyer next period, the more likely that agent will spend less when she is presently a buyer. Spending less money each successive time delivers more mass points in the distribution.

Since different buyer-seller ratios deliver different monetary distributions, this section concludes by comparing them with an empirical proxy of the distribution in the US. Following Chiu and Molico (2009), a distribution of checking account balances can be constructed using data from the 2004 Survey of Consumer Finance. The 10th and 90th percentiles of this distribution are reported in Table 3 along with the same percentiles of the models when $\mu$ is 2 percent. The table suggests that as the buyer-seller ratio increases, moments of the simulated monetary distribution approach moments of the empirical distribution. While this comparison is coarse, it is interesting to note that the data compares more favorably to buyer-seller ratios which deliver larger welfare costs of inflation. 

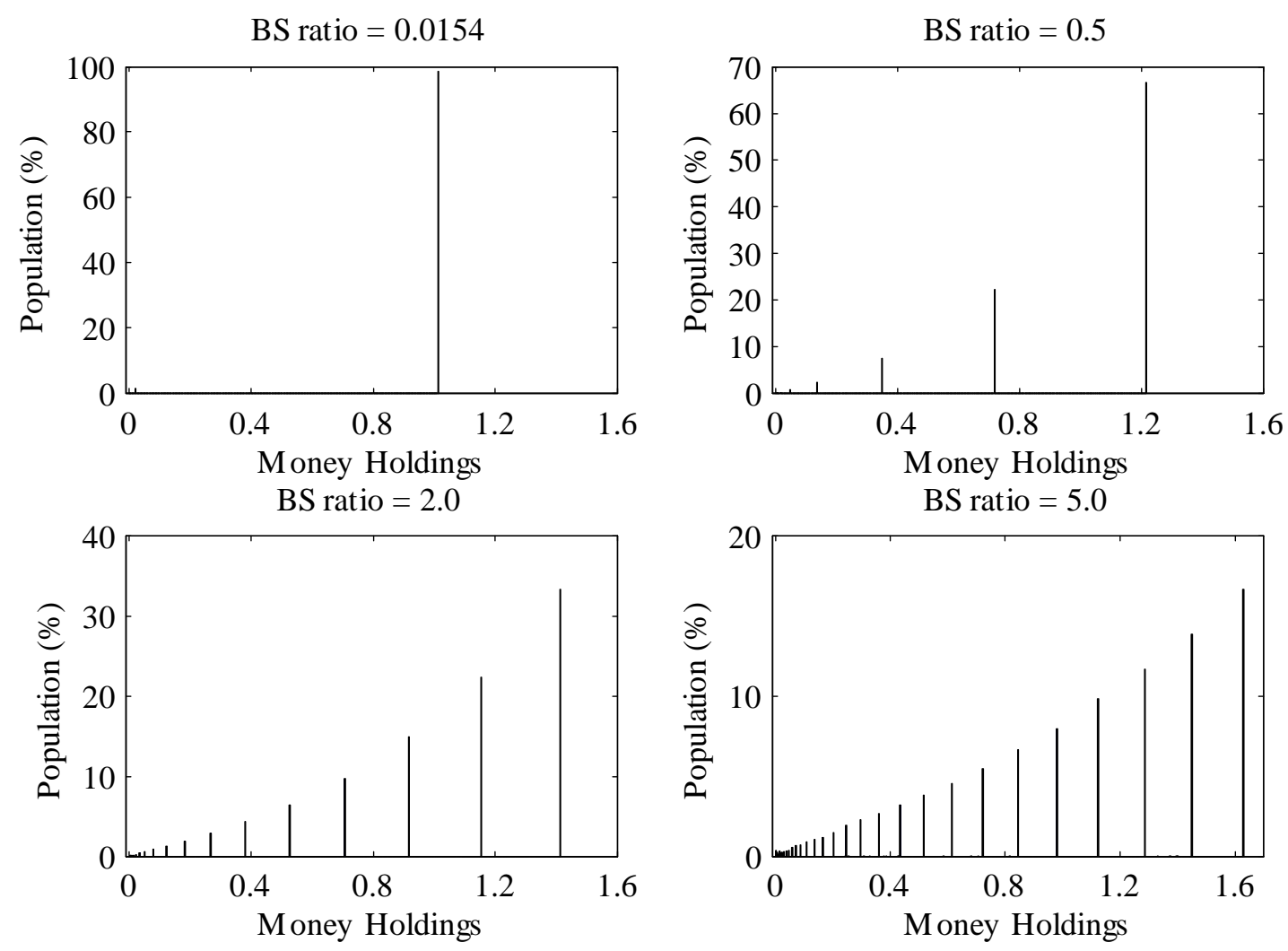

Figure 3: Monetary distributions under zero percent inflation; variable buyer-seller ratio. 
Table 2: Price and welfare results for variable buyer-seller ratios

\begin{tabular}{ccccccccccc}
\hline \hline$\mu$ & \multicolumn{2}{c}{$B / S \approx 0.0154$} & \multicolumn{3}{c}{$B / S \approx 0.5$} & \multicolumn{3}{c}{$B / S=1.0$} & \multicolumn{3}{c}{$B / S \approx 2.0$} & \multicolumn{2}{c}{$B / S \approx 5.0$} \\
\cline { 2 - 10 }$(\%$ ann.) & $P$ & $\mathrm{~W}$ & $P$ & $\mathrm{~W}$ & $P$ & $\mathrm{~W}$ & $P$ & $\mathrm{~W}$ & $P$ & $\mathrm{~W}$ \\
\hline 0.0 & 3.615 & 0 & 0.559 & 0 & 0.388 & 0 & 0.275 & 0 & 0.188 & 0 \\
0.5 & 3.980 & 0.102 & 0.604 & 0.049 & 0.423 & 0.055 & 0.309 & 0.063 & 0.221 & 0.071 \\
1.0 & 4.297 & 0.199 & 0.643 & 0.109 & 0.458 & 0.115 & 0.338 & 0.138 & 0.251 & 0.147 \\
2.0 & 5.081 & 0.374 & 0.719 & 0.210 & 0.524 & 0.232 & 0.395 & 0.261 & 0.308 & 0.299 \\
5.0 & 7.164 & 0.791 & 0.920 & 0.470 & 0.696 & 0.508 & 0.560 & 0.595 & 0.477 & 0.698 \\
10.0 & 10.633 & 1.306 & 1.241 & 0.862 & 0.974 & 0.924 & 0.824 & 1.049 & 0.764 & 1.231 \\
\hline \hline
\end{tabular}

Table 3: Empirical distributions of money holdings

\begin{tabular}{ccccccc}
\hline \hline Percentile & Data $^{a}$ & $B / S \approx 0.0154^{b}$ & $B / S \approx 0.5^{b}$ & $B / S=1.0^{b}$ & $B / S \approx 2.0^{b}$ & $B / S \approx 5.0^{b}$ \\
\hline 10th & 0.00 & 1.0154 & 0.244 & 0.262 & 0.226 & 0.055 \\
90th & 1.90 & 1.0154 & 1.255 & 1.376 & 1.545 & 1.930 \\
90th-10th & 1.90 & 0.000 & 1.011 & 1.114 & 1.319 & 1.875 \\
\hline
\end{tabular}

Notes: ${ }^{a}$ Checking acct. balances from 2004 Survey of Consumer Finances.

${ }^{b}$ Model simulations using $\mu=2 \%$ ann.

\subsubsection{Persistent States of Buying and Selling}

This section considers persistent types. It is assumed that the probability for an agent to remain her present type is equal across types (i.e. $\pi(e \mid e)=\sigma, \forall e \in E$ ). Having symmetric degrees of persistence results in the stationary distribution of agents across buyers and sellers to be equal for all $\sigma .{ }^{15}$ Therefore, the buyer-seller ratio will be equal to one and the results can be compared to the benchmark economy.

Three degrees of persistence are considered $(\pi(e \mid e)=0.25,0.75$, and 0.90). As with variable buyer-seller ratios, the parameter $\theta_{s}$ is re-calibrated to match velocity. For $\pi(e \mid e)=$ $0.25,0.75$, and $0.90, \theta_{s}$ is calibrated to $12.75,25.5$, and 27.3 , respectively. All other parameter values and functional forms are identical to the benchmark case.

Allowing for persistent types implies that agents are now heterogeneous with respect to both their individual money holdings and their probability of becoming a type $e$ agent

\footnotetext{
${ }^{15}$ Let $\sigma_{e}$ denote the stationary fraction of the population in state $e$. It can be shown that
}

$$
\sigma_{e}=\frac{1-\pi(e \mid e)}{2-\pi(e \mid e)-\pi(\tilde{e} \mid \tilde{e})}, \text { for } e \neq \tilde{e}
$$

Symmetry $(\pi(e \mid e)=\pi(\tilde{e} \mid \tilde{e}))$ results in $\sigma_{e}=1 / 2$. 
next period. In order to calculate expected welfare across agents, the welfare of each type of agent is weighted by the fraction of the population within that type. Since the Markov transition matrix is symmetric by assumption, the expected welfare in an environment with zero inflation is now given by

$$
\begin{gathered}
W_{P}(0)=\frac{1}{2} \int_{S} V(m, b ; P, 0) d \psi(0, e=b)+\frac{1}{2} \int_{S} V(m, s ; P, 0) d \psi(0, e=s) \\
W_{P}(0)=\left(\frac{1}{2}\right)\left[\frac{\beta}{(1-\beta \sigma)^{2}-\beta^{2}(1-\sigma)^{2}}\right] \times \\
{\left[\int_{0}^{\bar{m}}[\Phi U(x, y, b)+(1-\sigma) U(x, y, s)] d \psi(0, b)+\int_{0}^{\bar{m}}[(1-\sigma) U(x, y, b)+\Phi U(x, y, s)] d \psi(0, s)\right]}
\end{gathered}
$$

where $\Phi=\left(\sigma(1-\beta \sigma)+\beta(1-\sigma)^{2}\right)$. Note that when $\sigma=1 / 2$, this welfare calculation collapses to (7). Calculating the change in welfare given $\mu>0$ is analogous to (8).

The market price and welfare costs across degrees of persistence are reported in Table 4. As in all previous cases, prices are increasing in the inflation rate and welfare is decreasing for any given degree of persistence. Comparing the results across degrees of persistence, however, becomes slightly more complicated. There is a non-monotonic response of the market price across degrees of persistence. For example, prices are generally decreasing in the degree of persistence for relatively low levels of inflation (2 percent or lower). At higher rates of inflation, prices are decreasing up to a persistence level of 0.75 but increasing afterwards. The reason for this result is due to the model being calibrated under two percent inflation. As in all previous exercises, there is a positive relationship between market price and velocity. The relationship between monetary velocity and the money growth rate for all four degrees of persistence, however, are illustrated in Figure 4. Holding money growth fixed, velocity is decreasing in persistence up to two percent money growth, and increasing afterward. This suggests that the relationship between money growth and velocity is steeper as persistence gets larger, and this increase in velocity eventually delivers an increase in market price.

Welfare costs of inflation across degrees of persistence are more straightforward in that lower degrees of persistence are associated with higher welfare costs. For example, going from 
10 percent inflation to 0 percent is worth 2.169 percent of consumption when the probability of an agent remaining in her present state 25 percent. This cost is more than twice the benchmark case. When persistence is larger than the benchmark case, however, the welfare costs of inflation become welfare gains. In particular, when $\pi(e \mid e)=0.75$, welfare gains reach a maximum at an inflation rate between 5 and 10 percent. When $\pi(e \mid e)=0.90$, welfare gains continue past 10 percent inflation, but begin to diminish when $\mu=12.5{ }^{16}$

To shed some light on these results, welfare is decomposed among buyers and sellers and reported in Table 5. Explicitly, each component of the ratio in (9) is considered separately and the welfare cost / benefit for buyers and sellers are calculated independently. For all degrees of persistence, the welfare cost of inflation for sellers is higher than buyers because they are the agents presently accepting the asset which is depreciating in value. When the degree of persistence is larger than 50 percent, the table indicates that buyers are receiving the welfare gains of higher inflation while sellers continue to receive welfare costs. Sellers repeatedly have money holdings greater than average and therefore view inflation as tax. Buyers, on the other hand, repeatedly spend portions of their money holdings, have less than average, and view inflation as a subsidy. The total welfare effects are roughly an average of the two independent welfare effects and illustrate the trade off between the two types of agents. When $\pi(b \mid b)=0.75$ for example, a maximum in total welfare is achieved around $\mu=5.0$ because the increased costs to sellers eventually overpowers the increased benefits to buyers.

The monetary distributions are illustrated in Figure 5. For each degree of persistence, 50 percent of the agents are sellers which again explains the large right-tail. As states become more persistent, the distribution of buyers' money holdings is flatter and less segmented because they are spending less of their money holdings each period.

\footnotetext{
${ }^{16}$ When $\mu=12.5$, the model predicts $P=1.461$ and $W=1.953$.
} 


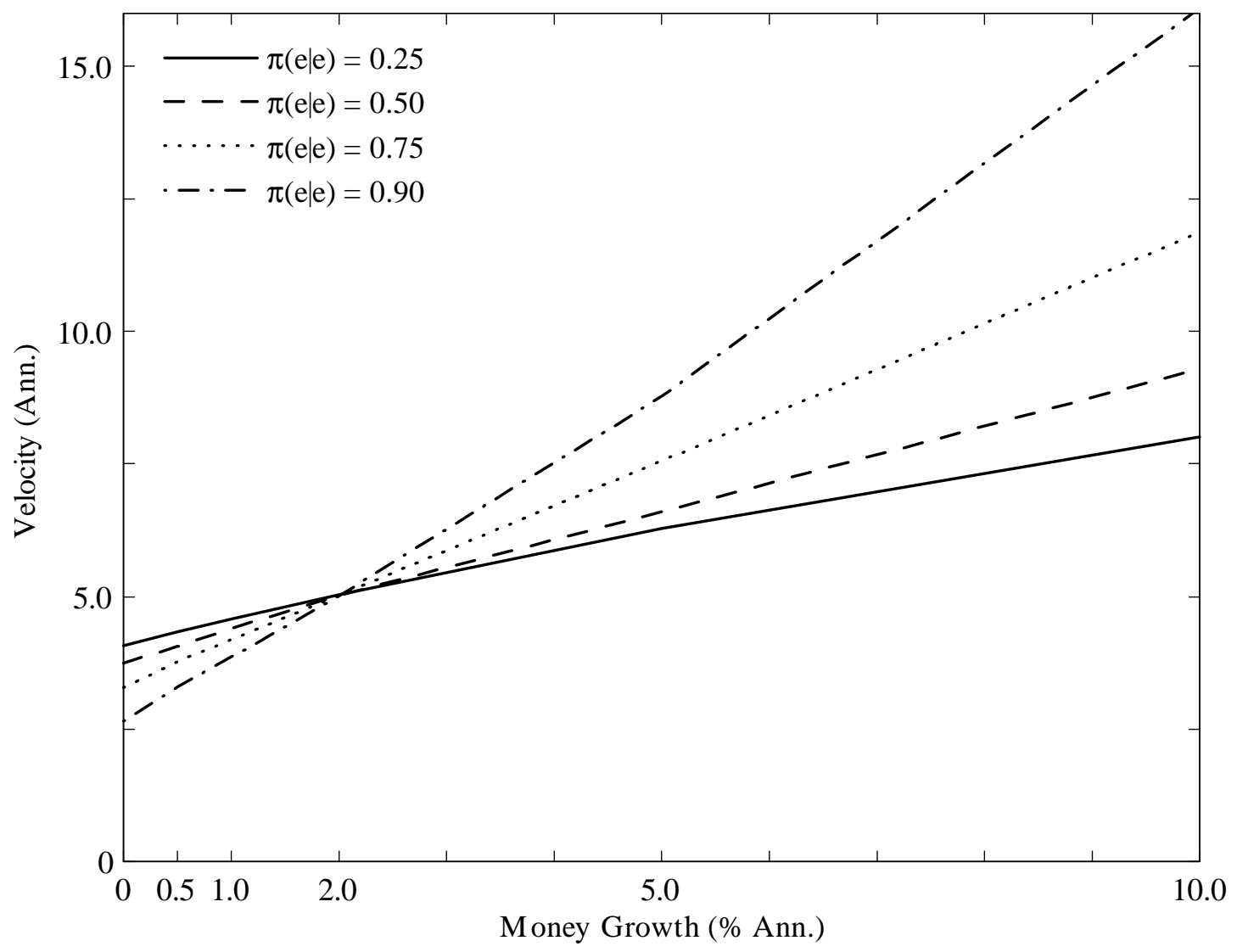

Figure 4: Annual velocity and money growth for persistent type-shocks. 

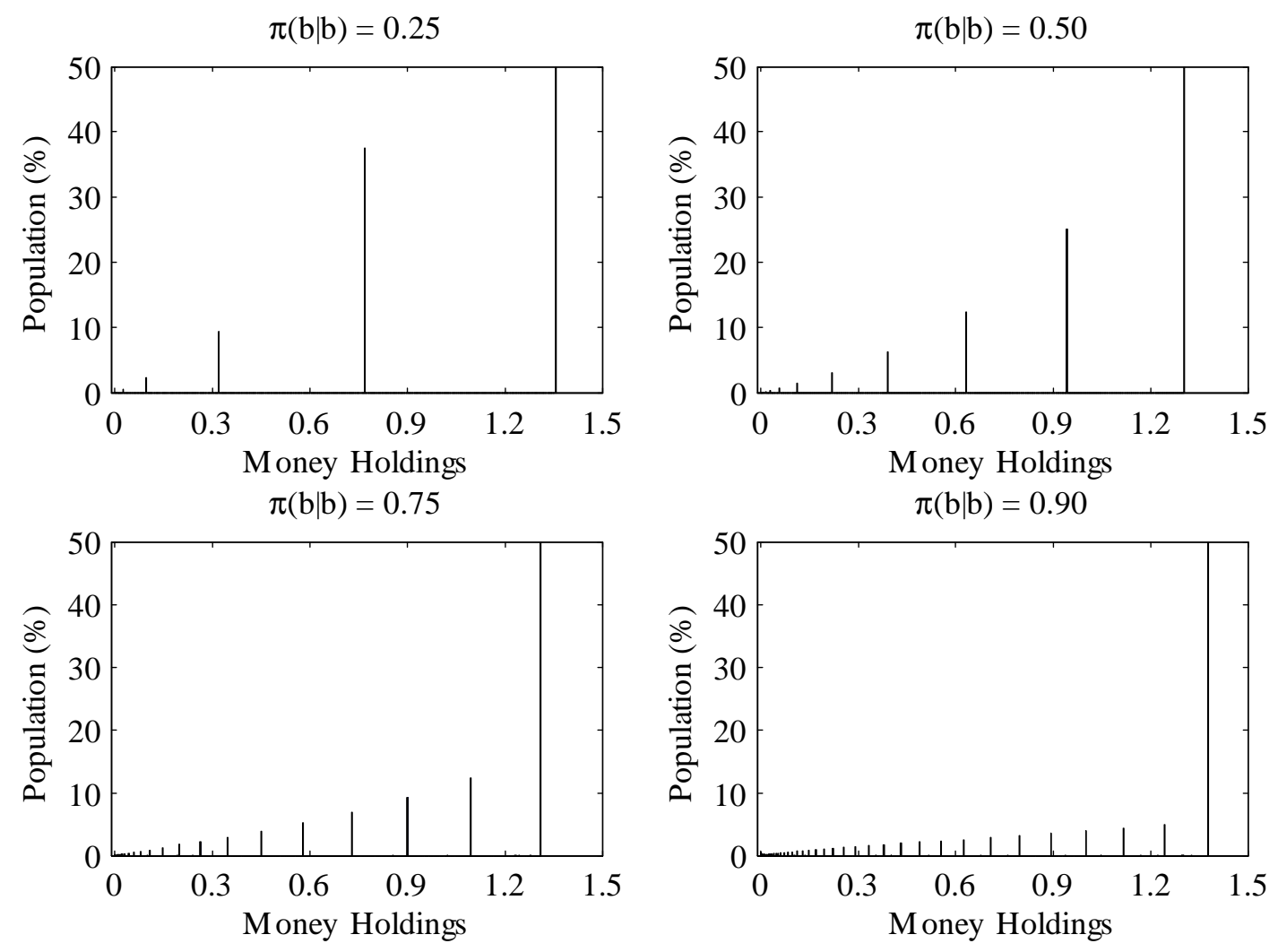

Figure 5: Monetary distributions under zero percent inflation; variable shock persistence. 
Table 4: Numerical results for persistent type shocks

\begin{tabular}{ccccccccc}
\hline \hline$\mu$ & \multicolumn{2}{c}{$\pi(b \mid b)=0.25$} & \multicolumn{2}{c}{$\pi(b \mid b)=0.50$} & \multicolumn{2}{c}{$\pi(b \mid b)=0.75$} & \multicolumn{2}{c}{$\pi(b \mid b)=0.90$} \\
\cline { 2 - 9 } (\% ann. & $P$ & $\mathrm{~W}$ & $P$ & $\mathrm{~W}$ & $P$ & $\mathrm{~W}$ & $P$ & $\mathrm{~W}$ \\
\hline 0.0 & 0.619 & 0 & 0.388 & 0 & 0.249 & 0 & 0.189 & 0 \\
0.5 & 0.660 & 0.160 & 0.423 & 0.055 & 0.286 & -0.063 & 0.235 & -0.393 \\
1.0 & 0.696 & 0.304 & 0.458 & 0.115 & 0.319 & -0.114 & 0.277 & -0.688 \\
2.0 & 0.767 & 0.579 & 0.524 & 0.232 & 0.383 & -0.191 & 0.361 & -1.121 \\
5.0 & 0.956 & 1.286 & 0.696 & 0.508 & 0.578 & -0.299 & 0.635 & -1.768 \\
10.0 & 1.223 & 2.169 & 0.974 & 0.924 & 0.913 & -0.282 & 1.169 & -1.990 \\
\hline \hline
\end{tabular}

Table 5: Welfare decomposition for persistent type shocks

\begin{tabular}{ccccccccc}
\hline \hline$\mu$ & $\pi(b \mid b)=0.25$ & \multicolumn{2}{c}{$\pi(b \mid b)=0.50$} & \multicolumn{2}{c}{$\pi(b \mid b)=0.75$} & \multicolumn{2}{c}{$\pi(b \mid b)=0.90$} \\
\cline { 2 - 9 } (\% ann. & $\mathrm{W}_{b}$ & $\mathrm{~W}_{s}$ & $\mathrm{~W}_{b}$ & $\mathrm{~W}_{s}$ & $\mathrm{~W}_{b}$ & $\mathrm{~W}_{s}$ & $\mathrm{~W}_{b}$ & $\mathrm{~W}_{s}$ \\
\hline 0.0 & 0 & 0 & 0 & 0 & 0 & 0 & 0 & 0 \\
0.5 & 0.108 & 0.213 & 0.057 & 0.059 & -0.133 & 0.003 & -0.899 & 0.003 \\
1.0 & 0.207 & 0.404 & 0.117 & 0.122 & -0.248 & 0.012 & -1.591 & 0.022 \\
2.0 & 0.411 & 0.750 & 0.231 & 0.241 & -0.433 & 0.036 & -2.636 & 0.076 \\
5.0 & 0.933 & 1.648 & 0.508 & 0.519 & -0.783 & 0.155 & -4.377 & 0.314 \\
10.0 & 1.645 & 2.707 & 0.924 & 0.939 & -1.020 & 0.412 & -5.395 & 0.749 \\
\hline \hline
\end{tabular}

\subsection{Additional Analyses}

\subsubsection{Quarterly and Monthly Frequencies}

The model can just as easily be analyzed in higher frequencies. The results of the benchmark case (no persistence, $\sigma=1 / 2$ ) for quarterly and monthly frequencies are reported in Tables 6 and 7 , respectively. The parameter $\theta_{s}$ was calibrated to 8.2 so quarterly velocity was roughly 1.25 at two percent money growth, and 3.4 so monthly velocity was roughly 0.42. The results discussed above generally hold for all frequencies considered: market price, the dispersion of money holdings, and monetary velocity are all increasing in the inflation rate, while the average amount consumed by buyers and welfare are decreasing.

\subsubsection{Nonlinear Labor Preferences}

Although the benchmark case considered linear labor preferences similar to Lagos and Wright, the model can just as easily be studied assuming nonlinear preferences with respect 
Table 6: Numerical results for benchmark economy, Quarterly Frequency

\begin{tabular}{ccccccc}
\hline \hline$\mu$ (\% ann.) & $P$ & $\operatorname{std}(m)$ & Velocity & $E\left(x_{b}\right)$ & $E\left(x_{s}\right)$ & Welfare (\%) \\
\hline 0 & 0.232 & 0.273 & 1.058 & 0.913 & 8.20 & 0 \\
0.5 & 0.244 & 0.283 & 1.111 & 0.905 & 8.20 & 0.038 \\
1.0 & 0.255 & 0.292 & 1.161 & 0.897 & 8.20 & 0.076 \\
2.0 & 0.277 & 0.308 & 1.256 & 0.883 & 8.20 & 0.150 \\
5.0 & 0.331 & 0.345 & 1.500 & 0.848 & 8.20 & 0.344 \\
10.0 & 0.407 & 0.390 & 1.832 & 0.800 & 8.20 & 0.629 \\
\hline \hline
\end{tabular}

Table 7: Numerical results for benchmark economy, Monthly Frequency

\begin{tabular}{ccccccc}
\hline \hline$\mu(\%$ ann. $)$ & $P$ & std $(m)$ & Velocity & $E\left(x_{b}\right)$ & $E\left(x_{s}\right)$ & Welfare (\%) \\
\hline 0 & 0.172 & 0.222 & 0.376 & 0.961 & 3.40 & 0 \\
0.5 & 0.178 & 0.228 & 0.388 & 0.958 & 3.40 & 0.027 \\
1.0 & 0.183 & 0.233 & 0.399 & 0.954 & 3.40 & 0.053 \\
2.0 & 0.193 & 0.242 & 0.420 & 0.948 & 3.40 & 0.104 \\
5.0 & 0.219 & 0.265 & 0.473 & 0.930 & 3.40 & 0.247 \\
10.0 & 0.255 & 0.294 & 0.549 & 0.904 & 3.40 & 0.488 \\
\hline \hline
\end{tabular}

to labor. Consider the utility function

$$
U(x, y, e)=\theta_{e} \log (x)-\left(\frac{C_{e} \chi}{1+\chi}\right) y^{\left(\frac{\chi+1}{\chi}\right)} .
$$

With $C_{s}=1, \chi$ represents the Frisch elasticity of labor supply. To be consistent with the exercises above, no attempt is made to calibrate this parameter. Instead, $\chi$ is set to 0.5 and $\theta_{s}$ is calibrated to 16.7 to match velocity. Having a Frisch elasticity of 0.5 follows Molico and Chiu (2009) and is consistent with empirical micro measures. ${ }^{17}$

The results of the model under zero percent inflation are illustrated in Figure 6. Compared to the benchmark case with linear labor, the obvious difference is that sellers are no longer choosing their consumption and future money holdings independently of their present money holdings due to the increasing marginal costs of production. Another result of nonlinear labor preferences is that the production of type $b$ agents becomes positive, but still remains small. Finally, the more dispersed decisions of the sellers delivers a distribution that

\footnotetext{
${ }^{17}$ One technical detail with convex labor preferences is that the marginal costs are lower than linear preferences for values less than one. Therefore, buyers are more willing to produce and the cost parameter $C_{b}$ was increased to $1.0 e^{6}$.
} 

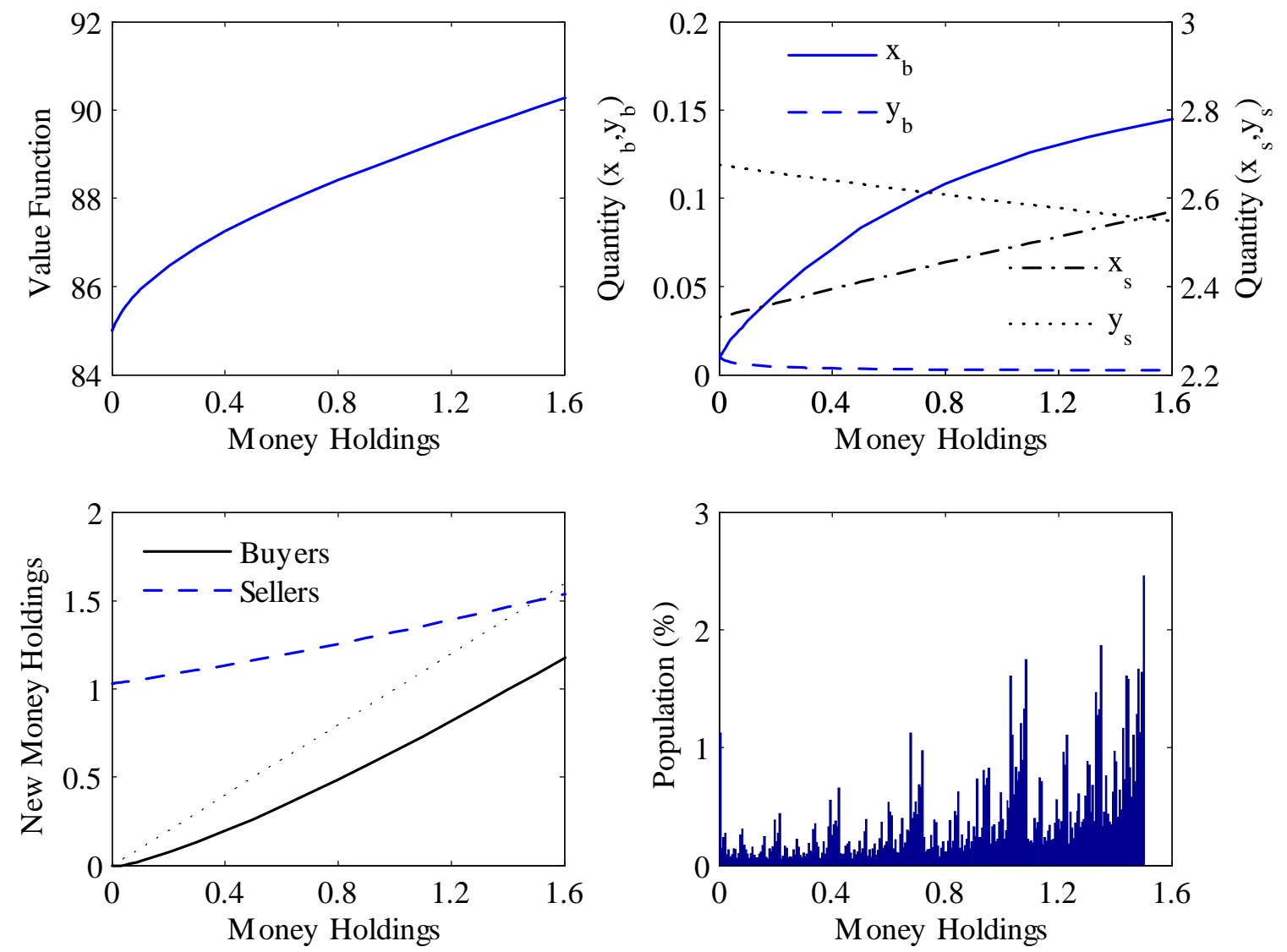

Figure 6: Economy with non-linear labor preferences under zero percent inflation.

has a similar shape to the benchmark case, but the nonlinearity results in less segmentation. Figure 7 illustrates further that although the distributions are less segmented, increases in the inflation rate make the distribution more dispersed just like the benchmark case.

Finally, the numerical results for the model are presented in Table 8. While nonlinear labor has large effects on prices and the average consumption of each agent type, there is surprisingly little change in the welfare costs. For example, the cost of 10 percent inflation is worth 0.948 percent of consumption in this model compared to 0.924 percent in the benchmark case. 

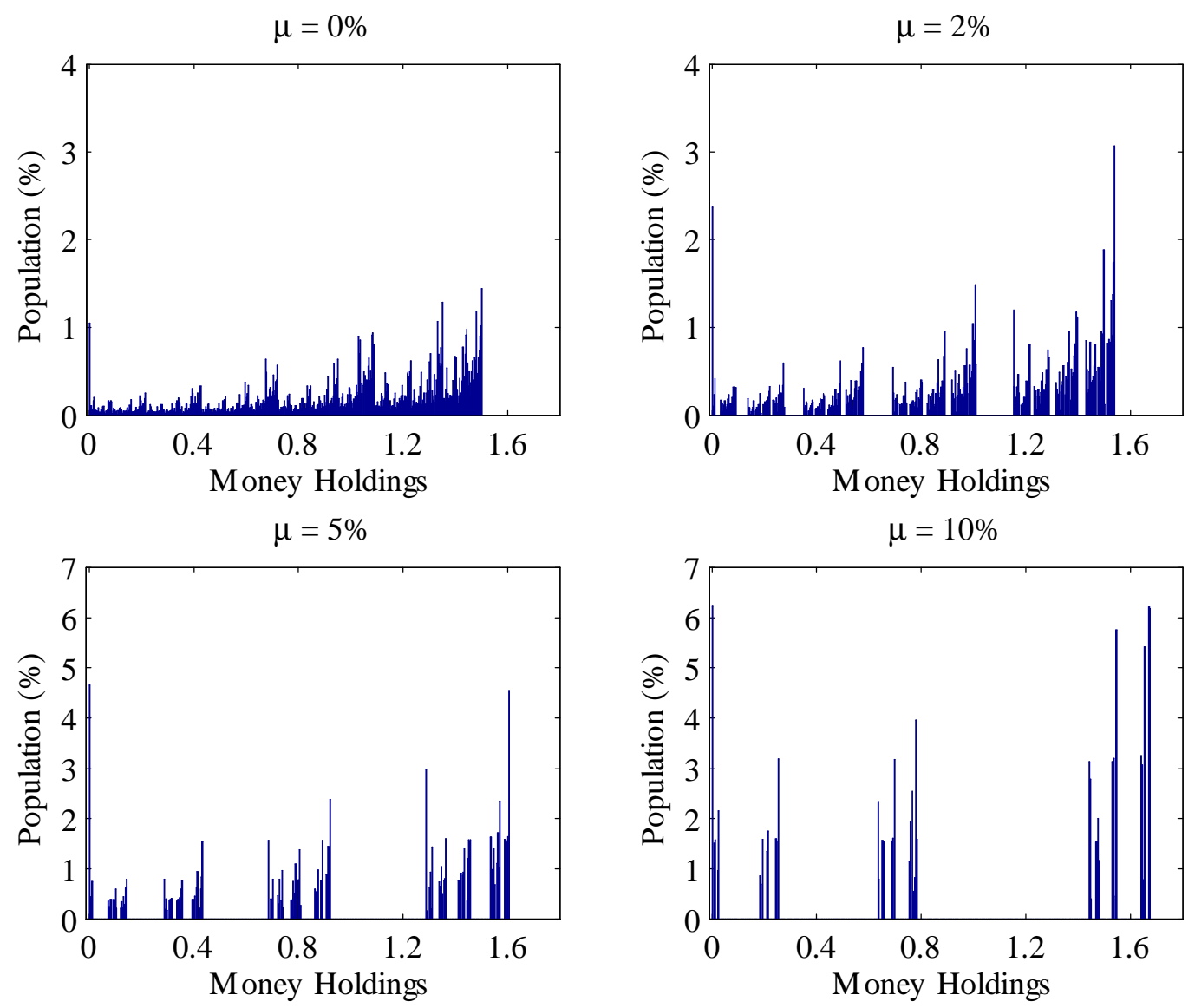

Figure 7: Monetary distributions for economy with non-linear labor preferences; variable inflation rates. 
Table 8: Numerical results for benchmark economy, Nonlinear Labor Preferences

\begin{tabular}{ccccccc}
\hline \hline$\mu$ (\% ann.) & $P$ & $\operatorname{std}(m)$ & Velocity & $E\left(x_{b}\right)$ & $E\left(x_{s}\right)$ & Welfare (\%) \\
\hline 0 & 2.986 & 0.410 & 3.873 & 0.114 & 2.483 & 0 \\
0.5 & 3.222 & 0.426 & 4.178 & 0.112 & 2.484 & 0.060 \\
1.0 & 3.455 & 0.441 & 4.478 & 0.109 & 2.486 & 0.119 \\
2.0 & 3.903 & 0.469 & 5.056 & 0.106 & 2.489 & 0.229 \\
5.0 & 5.197 & 0.539 & 6.724 & 0.096 & 2.495 & 0.533 \\
10.0 & 7.213 & 0.624 & 9.317 & 0.084 & 2.503 & 0.948 \\
\hline \hline
\end{tabular}

\section{Conclusion}

This paper quantitatively studies an environment where money is essential, and agents exchange in a Walrasian market with a competitively-determined price. All agents consume and can produce a homogeneous good, but hold money balances to purchase consumption in the event that they receive a low productivity shock. The model is calibrated to match longrun US velocity, and the welfare costs of inflation are assessed for variable buyer-seller ratios as well as persistent states of buying and selling. The welfare results can be summarized as generally increasing in the number of buyers relative to sellers, and decreasing in the persistence in the states of buying and selling. When states become more persistent that 50 percent, those who are persistently buyers receive welfare gains of inflation while those who are persistently sellers receive welfare costs. Further calculations of the model show that it is possible to obtain similar results for varying model frequencies as well as alternative (non-linear) labor preferences.

These results raise a number of compelling extensions. First, finding the relevant empirical moments to pin down a buyer-seller ratio, degree of type persistence, and shape of labor preferences will be very important for policy analysis. The model could then be used in a way similar to Lucas (2000) to deliver welfare costs of inflation which would be more reliable than the ones considered here. Second, given the relevant ease with which this model can be computed, it seems a reasonable environment to extend with additional assets similar to Aruoba et al. (2007), or a labor market similar to Berentsen et al. (2008). Finally, the most 
immediate extension of the present analysis is to consider the welfare effects of inflation in a dynamic setting similar to Krusell and Smith's (1998) analysis of the business cycle. These extensions are currently being explored.

\section{References}

[1] Aruoba, S. Boragan, Christopher J. Waller, and Randall Wright. (2007) "Money and Capital," FRB of Cleveland Working Paper No. 07-14.

[2] Ayagari, Rao. (1994) "Uninsured Idiosyncratic Risk and Aggregate Saving," Quarterly Journal of Economics 109, 659-684.

[3] Berentsen, Aleksander, Guido Menzio, and Randall Wright. (2008) "Inflation and Unemployment in the Long Run," NBER Working Paper No. W13924.

[4] Camera, Gabriele, and Dean Corbae. (1999) "Money and Price Dispersion," International Economic Review 40(4) (November), 985-1008.

[5] Chiu, Jonathan and Molico, Miguel. (2009) "Uncertainty, Inflation, and Welfare," Journal of Money, Credit, and Banking (forthcoming).

[6] Green, Edward J., and Ruilin Zhou. (1998) "A Rudimentary Random-Matching Model with Divisible Money and Prices," Journal of Economic Theory 81(2), 252-71.

[7] Green, Edward J., and Ruilin Zhou. (2002) "Dynamic Monetary Equilibrium in a Random Matching Economy," Econometrica 70(3) (May), 929-69.

[8] Huggett, Mark. (1993) "The Risk-Free Rate in Heterogeneous-Agent IncompleteInsurance Economies," Journal of Economic Dynamics and Control 17, 953-69.

[9] Kiyotaki, Nobuhiro, and Randall Wright. (1989) "On Money as a Medium of Exchange," Journal of Political Economics 97(4), 927-54.

[10] Kocherlakota, Narayana R. (1998) "Money is Memory," Journal of Economic Theory 81(2) (August), 232-51.

[11] Krusell, Per and Anthony A. Smith Jr. (1998) "Income and Wealth Heterogeneity in the Macroeconomy," Journal of Political Economy 106(5), 867-96.

[12] Lagos, Ricardo and Randall Wright. (2005) "A Unified Framework for Monetary Theory and Policy Analysis," Journal of Political Economy 113(3) (June), 436-84.

[13] Levine, David. (1991) "Asset Trading Mechanisms and Expansionary Policy," Journal of Economic Theory 54, 148-64. 
[14] Lucas, Robert E. Jr. and Edward C. Prescott. (1974) "Equilibrium Search and Unemployment," Journal of Economic Theory 7, 188-209.

[15] Lucas, Robert E. Jr. (2000) "Inflation and Welfare," Econometrica 68 (March), 247-74.

[16] Molico, Miguel. (2006) "The Distribution of Money and Prices in Search Equilibrium," International Economic Review 47(3) (August), 701-22.

[17] Mortensen, D.T. and C. A. Pissarides. (1994) "Job Creation and Job Destruction in the Theory of Unemployment," Review of Economic Studies 61, 397-415.

[18] Rocheteau, Guillaume and Randall Wright. (2005) "Money in Search Equilibrium, in Competitive Equilibrium, and in Competitive Search Equilibrium," Econometrica 73(1) (January), 175-202.

[19] Shi, Shouyong. (1997) "A Divisible Search Model of Fiat Money," Econometrica 65, $75-102$.

[20] Trejos, Alberto, and Randall Wright. (1995) "Search, Bargaining, Money, and Prices," Journal of Political Economy 103(1) (February), 118-41.

[21] Townsend, Robert M. (1980) "Models of Money is Spatially Separated Agents," in Models of Monetary Economies, J.H Kareken and N. Wallace (eds.). Minneapolis: Federal Reserve Bank of Minneapolis: 265-303.

[22] Wallace, Neil. (1980) "The Overlapping Generations Model of Fiat Money," in Models of Monetary Economies, J.H Kareken and N. Wallace (eds.). Minneapolis: Federal Reserve Bank of Minneapolis: 49-82.

[23] Zhou, Ruilin. (1999) "Individual and Aggregate Real Balances in a Random-Matching Model," International Economic Review 40(4), 1009-38.

[24] Zhu, Tao. (2003) "Existence of a Monetary Steady State in a Matching Model: Indivisible Money," Journal of Economic Theory 112(2) (October): 307-324.

[25] Zhu, Tao. (2005) "Existence of a Monetary Steady State in a Matching Model: Divisible Money," Journal of Economic Theory 123(2) (August): 135-60. 